\title{
Altered glycosylation and sialylation of serum proteins and lipid bound sialic acids in chronic renal failure
}

\author{
B. K. KISHORE \\ M.D.
}

\author{
F. GEJYO \\ M.D.
}

\author{
M. ARAKAWA \\ M.D.
}

Second Department of Internal Medicine, Niigata University School of Medicine, 1-754 Asahimachi-dori, Niigata 951, Japan

\begin{abstract}
Summary
Abnormalities in the metabolism of carbohydrates, lipids and proteins are well documented in chronic renal failure (CRF). We have studied the extent of glycosylation and sialylation of serum proteins and also the levels of lipid-bound sialic acids in nondiabetic patients with CRF maintained on haemodialysis. The total neutral sugar content (TNS) and the non-enzymatic glycosylation (NEG) of serum proteins, the protein-bound sialic acids (PSA) and the lipid-bound sialic acids (LSA) were found to be significantly elevated in the patients as compared to a group of healthy controls. A single dialysis therapy produced some alterations in these measurements. The TNS correlated significantly with the NEG and also with the PSA. No correlation existed between the PSA and LSA or between the LSA and serum total lipids. None of these measurements, however, correlated with the serum creatinine values. The established as well as putative pathophysiological consequences of these findings are discussed.
\end{abstract}

KEY WORDS: non-enzymatic glycosylation, $\mathrm{N}$-glycosylation, proteinbound sialic acids, lipid-bound sialic acids, chronic renal failure.

\section{Introduction}

The glycosylation of proteins, which is generally controlled by enzymes precisely, increases the range of properties of the proteins. However, recently the non-enzymatic glycosylation of proteins (NEG) has received considerable attention with its possible contribution to the secondary complications of diabetes mellitus (Bailey, 1981). In this post-translational protein modification, glucose reacts nonenzymatically with the $\mathrm{NH}_{2}$-terminal residues or forms keto-amine linkages with the $\varepsilon$-amino groups of certain lysyl residues. Although first described for haemoglobin in diabetes mellitus, it is now clear that all classes of serum proteins can be non-enzymatically glycosylated both in vitro and in vivo, and the extent of such a glycosylation appears to be a function of the duration of exposure and the concentration of glucose (Day, Thorpe and Baynes, 1979; Baynes, Day and Thorpe, 1979).

Sialic acids are involved in the social behaviour of cells. These are also essential for the structural and functional integrity of hormones such as the pituitary gonadotropins and erythropoietin (Stevenson and Lorain, 1971; Erslev, 1977). It is well established that sialic acid residues determine the survival of the circulating glycoproteins and glycolipids, the desialylated proteins and lipids being cleared faster from the circulation (Ashwell and Morell, 1974; Barkai and Di Cesare, 1975).

Lipid-bound sialic acids (LSA) or acidic glycosphingolipids or gangliosides are membrane components and participate in the internalisation of signals elicited by glycoprotein hormones, cholera toxin, interferon among others (Fishman and Brady, 1976). They also restrict the undesirable amplification of the alternative complement pathway reaction especially on self cell membranes (Okada, Yasuda and Okada, 1982).

The present work was undertaken following preliminary observations in our laboratory on sera of patients with chronic renal failure (CRF), that showed significant alterations in the protein to sialic acid ratio as compared to the control sera. In view of the known pathophysiological consequences that can result from the alterations in the glycosylation and sialylation of proteins, we have measured the total neutral sugar content (TNS) and NEG of serum proteins, the protein-bound sialic acids (PSA) and 
the lipid-bound sialic acids (LSA) in non-diabetic CRF patients maintained on regular haemodialysis.

\section{Materials and methods}

\section{Subjects}

CRF patients attending the dialysis units of the Niigata University and associated hospitals were selected randomly. The diagnosis was based on clinical approach, relevant laboratory investigations and renal biopsy. The pre-dialysis serum creatinine values were $1272 \pm 230 \mu \mathrm{mol} / 1$ (mean \pm s.d., $n=68$ ). All the patients studied were free from diabetes mellitus and their fasting blood sugar values were within normal limits. Twenty-six healthy adults served as controls.

\section{Collection of blood samples and assay methods}

Blood was collected from each patient just before the start and at the end of haemodialysis therapy. The plasma or serum* separated was stored at $-20^{\circ} \mathrm{C}$ until analysed. The TNS was measured by the anthrone reaction (Spiro, 1966), using pure dextrose (Wako Pure Chemical Ind., Japan) as standard. The PSA was assayed by the thiobarbituric acid method of Warren (1959) after acid hydrolysis with $0 \cdot 1 \mathrm{~N} \mathrm{H}_{2} \mathrm{SO}_{4}$ at $80^{\circ} \mathrm{C}$ for $1 \mathrm{hr}$. For these 2 assays, the serum proteins were precipitated by $5 \%$ trichloroacetic acid (TCA), centrifuged and the pellet was dissolved in an appropriate volume of $0.1 \mathrm{~N} \mathrm{NaOH}$. Aliquots of this preparation were used to avoid the interference caused by free glucose and certain amino acids in the case of anthrone reaction, and the elevated non-proteinaceous thiobarbituric acid reac-

\footnotetext{
*Usually, the pre-dialysis samples are serum and post-dialysis ones plasma due to the heparin that is administered during dialysis. Hence the terms 'plasma' or 'serum' are used without any distinction in this paper.
}

tive materials (Fillit et al., 1981) in the case Warren's method. The NEG was measured accorof ing to the method adapted by McFarland et at: (1979), using 5-hydroxymethylfurfural (Waks Chemicals, Japan) as standard. For this, the plasma samples were dialysed first to prevent spuriots elevation of NEG due to the free glucose. The LS were estimated by an improved Katopodis and Stock (1980) method. Protein in the dialysed serum samples and the reconstituted TCA precipitates was measured by the method of Lowry et al. (1951), using crysta line bovine serum albumin (Sigma Chemical $\mathrm{Co} \overrightarrow{\mathrm{H}}$ Missouri, U.S.A.) as the standard. Serum total lipids were assayed by the sulphophosphovanillin method (Zöllner and Kirsch, 1962), using a pooled humaت serum of known lipid content as the standard. Ni acetylneuraminic acid used as a standard in the assay of PSA and LSA was purchased from the Fluka AEg Buchs, Switzerland. All other chemicals used were of the highest purity available in Japan, and a Hitach Model 200-20 Spectrophotometer was employed for the absorbance readings.

Relationship between the variables was assessect from the correlation coefficients and the differences between the means by the Student's $t$-test (Snedocof and Cochran, 1978). Standard deviation (s.d.) wass used to express dispersion.

\section{Results}

Table 1 gives the mean \pm s.d. values for the 4 assays as well as the serum total lipid content in the controli and the patients with CRF. There was a statisticali significant elevation of all the values in both pre- and post-dialysis samples as compared to the controls However, the TNS and NEG were significantly reduced and the LSA elevated after a single dialysi therapy. There was no significant hyperlipidaemia in the patients. The scattergrams (Fig. 1, 2) depict the PSA and LSA values in the individual patients.

TABLE 1. The total neutral sugar content of serum proteins (TNS), the non-enzymatically glycosylated serum proteins (NEG), protein-bound sialic acids (PSA), lipid-bound sialic acids (LSA) and serum total lipids (TL) in controls and in patients with chronic renal failure [Results arê expressed as mean \pm s.d. $(n)]$

\begin{tabular}{|c|c|c|c|c|c|}
\hline Group & $\begin{array}{c}\text { TNS } \\
\text { ( } \mu \mathrm{g} \text { dextrose/mg } \\
\text { serum protein) }\end{array}$ & $\begin{array}{c}\text { NEG } \\
\text { (nmoles HMF/mg } \\
\text { serum protein) }\end{array}$ & $\begin{array}{c}\text { PSA } \\
(\mu \mathrm{g} / \mathrm{mg} \text { of serum } \\
\text { protein })\end{array}$ & $\underset{(\mathrm{mg} / \mathrm{dl})}{\text { LSA }}$ & $\underset{(\mathrm{mg} / \mathrm{dl})}{\mathrm{TL}}$ \\
\hline Controls & $5.46 \pm 0.61(26)$ & $0.097 \pm 0.021(26)$ & $7 \cdot 59 \pm 2.02(26)$ & $16 \cdot 15 \pm 1 \cdot 21$ & $586 \pm 125(20)$ \\
\hline $\begin{array}{l}\text { Chronic renal failure } \\
\text { Pre-dialysis } \\
\text { Post-dialysis }\end{array}$ & * $\left[\begin{array}{c}11 \cdot 24 \pm 3.74(68)^{*} \\
8.25 \pm 3.58(68)^{*}\end{array} \dagger\right.$ & {$\left[\begin{array}{lll}0.163 \pm 0.051(30)^{*} & \\
0.123 \pm 0.061 & (30) \ddagger\end{array}\right.$} & {$\left[\begin{array}{c}10.90 \pm 3.84(68)^{*} \\
9.73 \pm 3.68(68)^{*}\end{array}\right.$} & {$\left[\begin{array}{l}17.91 \pm 2.57(45)^{*} \\
20.51 \pm 4.17(45)^{*}\end{array}\right.$} & $\begin{array}{l}506 \pm 229(45) \\
623 \pm 381(45)\end{array}$ \\
\hline \multicolumn{6}{|c|}{$\begin{array}{l}* P<0.001 ; \dagger P<0.01 ; \ddagger P<0.05 ; 80 \cdot 1<P>0.05 ; \text { HMF: } 5 \text {-hydroxymethylfurfural. } \\
\text { The statistical significance of pre-and post-dialysis values as compared to controls at different levels of ' } P \text { ' are earmarked on the upper righ } \\
\text { corner, whereas the symbol adjacent to the vertical bars on the left of the values shows the significance of difference between the pre- and } \\
\text { post-dialysis samples. }\end{array}$} \\
\hline
\end{tabular}




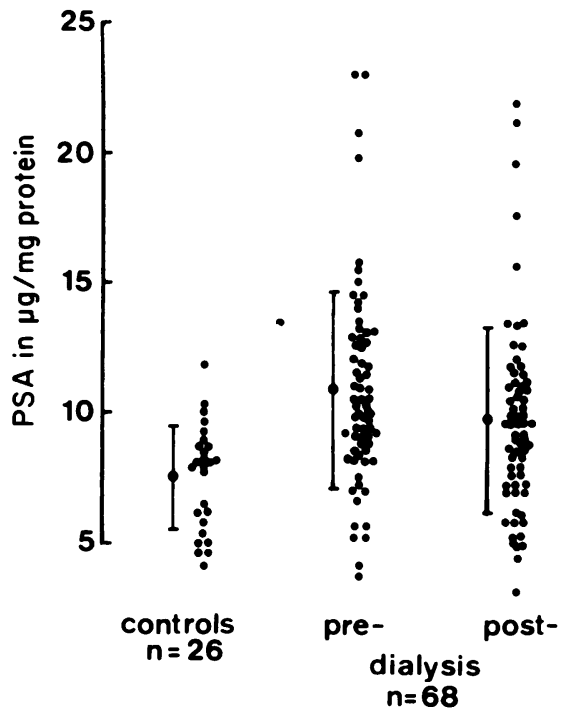

FIG.1. Scattergram of levels of PSA in controls and pre- and postdialysis serum samples of CRF patients. Mean \pm s.d. are indicated by vertical bars:

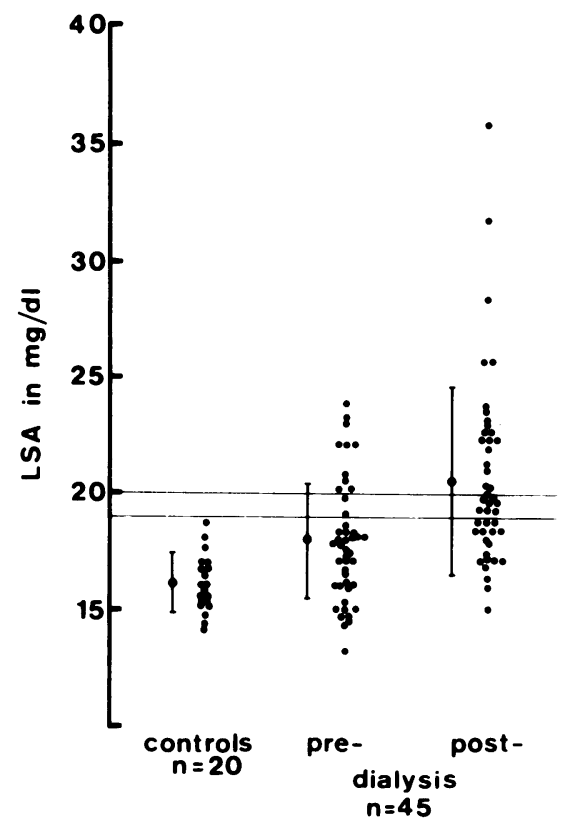

FIG. 2. Scattergram of levels of LSA in controls and pre- and postdialysis serum samples of CRF patients. Mean \pm s.d. are indicated by bars. The upper horizontal line demarcates the upper limit of normal $(20 \mathrm{mg} / \mathrm{dl})$ as adapted by other workers, while the lower one shows the upper limit of normal observed in our study $(19 \mathrm{mg} / \mathrm{dl})$.

Although there is a considerable overlap of values between the controls and the patients, there is a clear evidence for a tendency towards higher values in the patients.

Table 2 gives the zero order correlation coefficients between the results of the assays. Statistically significant direct correlations were found between the TNS and NEG and also between the TNS and PSA in both the pre- and post-dialysis samples. There was no correlation either between the TNS and LSA or between the serum total lipids and the LSA $(r=-0.153$ in pre-dialysis samples and $r=-0.081$ in post-dialysis samples). Further, no correlation could be found between the serum creatinine levels and any of the parameters studied.

TABLE 2. Zero order correlation coefficients between the total neutral sugar content of serum proteins (TNS), non-enzymatically glycosylated serum protein (NEG), protein-bound sialic acids (PSA) and lipid-bound sialic acids (LSA) in the pre- and post-dialysis serum samples of the chronic renal failure patients

\begin{tabular}{|c|c|c|c|}
\hline \multirow[b]{2}{*}{ Variable } & \multicolumn{3}{|c|}{ Variable } \\
\hline & NEG & PSA & LSA \\
\hline TNS & $\begin{array}{l}\text { (a) } 0.441 \dagger \\
\text { (b) } 0.682^{*} \\
(n=30)\end{array}$ & $\begin{array}{l}\text { (a) } 0.464^{*} \\
\text { (b) } 0.524^{*} \\
(n=67)\end{array}$ & $\begin{array}{c}\text { (a) }-0.004 \\
\text { (b) }-0.164 \\
(n=45)\end{array}$ \\
\hline NEG & & $\begin{array}{l}\text { (a) } 0.293 \ddagger \\
\text { (b) } 0.458 \dagger \\
(n=30)\end{array}$ & $\S$ \\
\hline PSA & & & $\begin{array}{l}\text { (a) } 0.146 \\
\text { (b) } 0.218 \\
(n=45)\end{array}$ \\
\hline
\end{tabular}

(a) pre-dialysis samples; (b) post-dialysis samples; ${ }^{*} P<0.001$; $\dagger 0.01<P>0.02 ; \ddagger 0.1<P>0.2 ;$ \&Could not be determined due to small sample size.

\section{Discussion}

Bailey (1981) has concisely reviewed the chemistry, mechanism of formation and the established, as well as the possible, consequences of NEG of proteins with reference to the pathophysiological changes seen in diabetes mellitus. Briefly, the secondary complications of diabetes mellitus, which accounts for most of the mortality and morbidity, involve organs such as the lens, peripheral nerves, kidney, retina and blood vessels. And interestingly, these organs are not dependent on insulin for glucose uptake and therefore are subjected to high intracellular glucose concentrations during periods of hyperglycaemia. The secondary complications are due to the modification of the properties of the proteins.

The abnormalities in the carbohydrate metabolism in CRF are to some extent similar to those of diabetes mellitus. Glucose intolerance occurs in about $70 \%$ of patients with CRF. Although the fasting blood sugar values of CRF patients are usually normal, the postprandial levels are elevated. Plasma insulin levels in 
response to intravenously administered glucose are normal or accentuated, suggesting that glucose intolerance is a result of peripheral resistance to insulin (Alfrey, 1980). The concentration of NEG observed in our patients is about 1.5 times, whereas that reported in diabetes is 2-3 times as high as in healthy controls (McFarland et al., 1979; Bailey, 1981). Although at present it is not possible to correlate our observations on NEG with the pathophysiological changes seen in CRF, at least 2 of the organs listed above with reference to diabetes, namely peripheral nerves and blood vessels, are involved in long standing CRF, calling for further longitudinal studies to evaluate the contribution of NEG for CRF complications. Glycosylation can modify the physical, biochemical and immunological properties of proteins. Evidence is accumulating that NEG of lowdensity lipoproteins (LDL) can markedly change its properties. The lysyl residues primarily involved in the $\mathrm{N}$-glycosylation of LDL are on or near the important residues of LDL that control the interaction of LDL with its receptors (Kim and Kurup, 1982). In vitro studies with cultured human fibroblasts have shown that glycosylated LDL was internalised and degraded significantly less than the control $\mathrm{LDL}$, in proportion to the estimated degree of glycosylation (Gonen et al., 1981). Glycosylated LDL is a poor stimulator of cholesteryl ester synthesis by cultured human fibroblasts. These preliminary in vitro observations on $\mathrm{N}$-glycosylated LDL are significant in view of the accelerated atherosclerosis in diabetes and CRF.

Kirschbaum (1975) reported an increase in the activities of the enzymes glycoprotein:glycosyl transferase and glycoprotein:sialic acid transferase in CRF. This lends further support to our observations on PSA. Kirschbaum (1975) suggested that the increased activity of the enzymes in CRF might be due to altered intracellular environment or the reduced availability of nucleotide sugar precursors. However, we would like to speculate that there might be a possible derangement in the biosynthetic pathway for sialic acids, resulting in increased biosynthesis and incorporation of these into glycoproteins and glycolipids. Serum levels of pyruvate are elevated in uraemia with a possible block in the production of lactate and acetyl coenzyme A (Galloway and Morgan, 1964). The accumulating pyruvate, through oxaloacetate, can give rise to phosphoenolpyruvate, one of the precursors in the biosynthesis of $\mathrm{N}$ acetylneuraminic acid, the principal sialic acid in man (Mayes, 1979). Hypersialylation of serum proteins in CRF can prolong the life-span of serum glycoproteins and this further enhances the NEG to occur, as one of the parameters that controls the rate of NEG, as mentioned in the introduction, is the duration of the exposure. In addition, it has been shown that type $\mathrm{V}$ hyperlipoproteinemia is associate with an abnormal preponderance of sialylated to the desialylated apolipoprotein C III in triglyceride-rich lipoproteins, presenting evidence for the possibe involvement of sialic acids in hyperlipoproteinemias (Kashyap et al., 1981).

LSA are reported to be elevated in a number of malignant conditions (Dnistrian and Schwartz, 198 and it is speculated that they reflect the release and accumulation of tumour products like the cell surface antigens. It is hard to imagine such a mechanis $\vec{B}$ operating in renal failure. Elevation of LSA in nonmalignant conditions is very rare (Katopodis anch Stock, 1980) and at present the cause for its elevatiog in CRF is not clear. The increased mean value of LSA in post-dialysis samples over that of pre-dialysis. ones (Fig. 2) might be due to haemoconcentration that occurs during dialysis. The findings of serues total lipids within normal limits and the non significant correlation between the serum total lipids and LSA rules out the possibility of hyperlipidaemia as a cause of elevated LSA in our patients.

In conclusion, we have shown that in CRF, the neutral sugar content and the non-enzymatic glycos sylation of serum proteins are increased, probably a result of glucose intolerance and other derange ments in the metabolism of sugars. The cause for dhe $^{2}$ hypersialylation of serum glycoproteins and glyglit pids needs further investigation. The possible pater physiological consequences of these findings 8 re discussed.

\section{Acknowledgments}

Dr Kishore is a recipient of a Research Fellowship from the Ministry of Education, Science \& Culture (MOMBUSHO), Japal Thanks are due to Ms Kaneko for her help during the preparation of this manuscript.

\section{References}

Alfrey, A.C. (1980) Chronic renal failure: manifestations and pathogenesis. In: Renal and Electrolyte Disorders (Ed. R.W Schrier), 2nd edn., p. 409. Little, Brown \& Co., Boston.

ASHWELL, G. \& MORELL, A.G. (1974) The role of surface carboh drates in the hepatic recognition and transport of circulatis glycoproteins. Advances in Enzymology, 41, 99.

BAILEY, A.J. (1981) The non-enzymatic glycosylation of protei Hormone and Metabolic Research, 11 (Suppl.), 90.

BARKAI, A. \& DI CESARE, J.L. (1975) Influence of sialic acid groups on the retention of glycosphingolipids in blood plasma. Biochirh? ica et Biophysica Acta, 398, 287.

BAYNES, J.W., DAY, J.F. \& THORPE, S.R. (1979) Non-enzymatiG glycosylation of rat serum proteins in vitro and in vivo. Federation? Proceedings, 38, 418.

DAY, J.F., THORPE, S.R. \& BAYNES, J.W. (1979) Non-enzymaticall glycosylated albumin. Journal of Biological Chemistry, 254, 595

Dnistrian, A.M. \& Schwartz, M.K. (1981) Plasma lipid bounf sialic acid and carcinoembryonic antigen in cancer patients. Clinical Chemistry, 27, 1737. 
ERSLEv, A.J. (1977) Production of erythrocytes. In: Hematology (Eds. W.J. Williams, E. Beutler, A.J. Erslev \& R.W. Rundles), 2nd edn., p. 203. McGraw-Hill Book Co., New York.

Fillit, H., Elion, E., Sullivan, J., Sherman, R. \& Zabriskie, J.B. (1981) Thiobarbituric acid reactive material in uremic blood. Nephron, 29, 40.

FISHMAN, P.H. \& BRADY, R.O. (1976) Biosynthesis and functions of gangliosides. Science, 194, 906.

GallowaY, R.E. \& MORGAN, J.M. (1964) Serum pyruvate and lactate in uremia. Metabolism, 13, 818.

Gonen, B., BAenziger, J., Schonfeld, G., Jacobson, D. \& FARRAR, P. (1981) Nonenzymatic glycosylation of low density lipoproteins in vitro. Effect on cell-interactive properties. Diabetes, 30, 875 .

KaShyap, M.L., Hynd, B.A., Robinson, K. \& GARTSIDE, P.S. (1981) Abnormal preponderance of sialylated apolipoprotein C III in triglyceride rich lipoproteins in type $\mathrm{V}$ hyperlipoproteinemia. Metabolism, 30, 111.

KATOPODIS, N. \& STOCK, C.C. (1980) Improved method to determine lipid bound sialic acid in plasma or serum. Research Communications in Chemical Pathology and Pharmacology, 30, 171.

KIM, H.J. \& KURUP, I.V. (1982) Non-enzymatic glycosylation of human plasma low density lipoprotein: Evidence for in vitro and in vivo glucosylation. Metabolism, 31, 348.

KIRSCHBAUM, B.B. (1975) Glycoprotein metabolism in human renal disease: serum glycoproteins and glycoprotein:glycosyl transferase levels in chronic renal failure. Journal of Laboratory and Clinical Medicine, 86, 764.
LOWRY, O.H., Rosenbrough, N.J., FARR, A.L. \& RANDAL, R.J. (1951) Protein measurement with Folin phenol reagent. Journal of Biological Chemistry, 193, 265.

MAYES, P.A. (1979) Metabolism of carbohydrate. In: Review of Physiological Chemistry (Eds. H.A. Harper, V.W. Rodwell \& P.A. Mayes), 17th edn., p. 294. Lantz Medical Publication, California.

MCFARland, K.F., Catalano, E.W., Day, J.F., ThorPE, S.R. \& BAYNES, J.W. (1979) Nonenzymatic glycosylation of serum proteins in diabetes mellitus. Diabetes, 28, 1011.

OKADA, N., YASUDA, T. \& OKADA, H. (1982) Restriction of alternative complement pathway activation by sialosylglycolipids. Nature, 299, 261.

SNEDOCOR, G.W. \& CochRAN, W.G. (1978) Statistical Methods 6th edn. Iowa State University Press. Ames.

SPIRO, R.G. (1966) Analysis of sugars found in glycoproteins. In: Methods in Enzymology (Eds. E.P. Neufeld \& V. Ginsburg), Vol. VII:3. Academic Press, New York.

SteVenson, P.M. \& LoRAINE, J.A. (1971) Pituitary gonadotropins -chemistry, extraction and immunoassay. Advances in Clinical Chemistry, 14, 1.

WARREN, L. (1959) The thiobarbituric acid assay of sialic acids Journal of Biological Chemistry, 234, 1971.

ZOLlNER, N. \& KIRSCH, U.K. (1962) Uber die quantitative Bestimmung von Lipoiden (Mikromethode) mittels der vielen naturlichen Lipoiden (allen bekannten plasmalipoiden) gemeinsamen Sulfophosphovanillin Reaktion. Zeitschrift fur die gesamte experimentelle Medizin, 135, 545.

(Accepted 9 March 1983) 